Florida International University

FIU Digital Commons

Electrical and Computer Engineering Faculty

Publications

$5-30-2019$

\title{
Hydrothermal Growth of Zinc Oxide (ZnO) Nanorods (NRs) on Screen Printed IDEs for $\mathrm{pH}$ Measurement Application
}

Aksaya Kumar A.

Naveen Kumar S.K.,

Almaw Ayele Aniley

Renny Edwin Fernandez

Shekhar Bhansali

Follow this and additional works at: https://digitalcommons.fiu.edu/ece_fac

Part of the Electrical and Computer Engineering Commons

This work is brought to you for free and open access by the College of Engineering and Computing at FIU Digital Commons. It has been accepted for inclusion in Electrical and Computer Engineering Faculty Publications by an authorized administrator of FIU Digital Commons. For more information, please contact dcc@fiu.edu. 


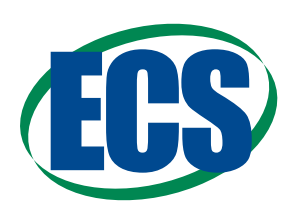

JES Focus ISSUE ON 4D MATERIALS AND SYSTEMS

\title{
Hydrothermal Growth of Zinc Oxide (ZnO) Nanorods (NRs) on Screen Printed IDEs for $\mathbf{p H}$ Measurement Application
}

\author{
Akshaya Kumar A., ${ }^{1, z}$ Naveen Kumar S. K., ${ }^{1}$ Almaw Ayele Aniley, ${ }^{1,2}$ \\ Renny Edwin Fernandez, ${ }^{3}$ and Shekhar Bhansali ${ }^{4}{ }^{4, *}$ \\ ${ }^{1}$ Mangalore University, Department of Electronics, Mangalagangothri, 574199 Mangalore, India \\ ${ }^{2}$ School of Electrical and Computer Engineering, Debre Markos University, Debre Markos, Ethiopia \\ ${ }^{3}$ R.B. Annis School of Engineering, University of Indianapolis, Indianapolis, Indiana 42664, USA \\ ${ }^{4}$ Department of Electrical and Computer Engineering, Florida International University, Miami, Florida 33174, USA
}

\begin{abstract}
There is considerable interest in nanostructured materials with interdigitated electrodes (IDEs) platforms to detect and monitor the level of various ions in numerous applications. Herein, we report the design and fabrication of IDEs based $\mathrm{pH}$ sensor by using hydrothermal growth of $\mathrm{ZnO}$ nanorods (NRs). A four-step deposition of $\mathrm{ZnO}$ seed layer followed by a hydrothermal treatment lead to the heavily ordered $\mathrm{ZnO}$ NRs patterns on the screen printed IDEs. The structural, chemical compositional and electrical properties of the NRs were investigated and examined by using field emission scanning electron microscopy (FeSEM), atomic force microscopy (AFM), energy dispersive spectroscopy (EDS), X-ray diffraction (XRD) technique and Keithley 4200 semiconductor characterization system respectively. The sensor capacitance and $\mathrm{pH}$ were found to be inversely proportional at a working frequency of $1 \mathrm{kHz}$. The sensor displayed sensitivity of $1.06 \mathrm{nF} / \mathrm{pH}$ in the range of $\mathrm{pH} 4-10$.

(C) The Author(s) 2019. Published by ECS. This is an open access article distributed under the terms of the Creative Commons Attribution 4.0 License (CC BY, http://creativecommons.org/licenses/by/4.0/), which permits unrestricted reuse of the work in any medium, provided the original work is properly cited. [DOI: 10.1149/2.0431909jes]

(cc) BY
\end{abstract}

Manuscript submitted February 14, 2019; revised manuscript received May 15, 2019. Published May 30, 2019. This paper is part of the JES Focus Issue JES Focus Issue on 4D Materials and Systems.

$\mathrm{pH}$ is a crucial parameter in regulating the reactivity of many chemical physical and biological species, thus its measurement is fundamental need in many fields ranging from agriculture ${ }^{1,2}$ and environmental science to chemical engineering ${ }^{3}$ and food science to biology and health applications. .,5,6,7,8 Numerous attempts have been made to detect the $\mathrm{pH}$ concentration using different methods like glass probe based $\mathrm{pH}$ electrodes, ${ }^{9}$ ion selective electrodes (ISEs) ${ }^{10,11}$, ion selective field effect transistor (ISFET) $\mathrm{pH}$ sensors ${ }^{12,4}$ need pre conditionally prepared samples in laboratories, hence there is a time delay in processing and it will cause to the decreases in sensor detection performance.

Recently interdigitated electrodes (IDEs) based electrochemical $\mathrm{pH}$ sensors have attracted the interest of researchers due to their advantageous features i.e. small size, easy to operate, high sensitivity, fast response and economic with the lower cost of fabrication. ${ }^{13,14,15,16}$ The emerging field of nanosensors, metal oxides based active nanolayers with IDEs structures on the variety of degradable substrates can easily detects the specific ion reactions. ${ }^{17,18,15,19,20}$

In addition, nanostructured materials are offering the large surface to volume ratio to the specific ionic reactions and thereby improve the sensor performance. Among metal oxides, Zinc oxide $(\mathrm{ZnO})$ is more versatile and widely studied metal oxide material due to easy synthesis method at room temperature and which exhibits the excellent physical, chemical, electrical and optoelectronic properties. One-dimensional (1D) Zinc oxide $(\mathrm{ZnO})$ which has a direct wide bandgap $(3.37 \mathrm{eV})$ semiconductor with a large excitation binding energy $(60 \mathrm{meV})$ at room temperature. The hydrothermal growing method is a simple and easy synthesis method to develop various nanostructures of $\mathrm{ZnO}$ for various applications. $^{21,22,23,24,25}$

We present a fabrication of $\mathrm{ZnO}$ NR based IDEs sensor for continuous electrochemical detection of $\mathrm{pH}$. The Copper $(\mathrm{Cu})$ based IDEs structure built using CIRCAD design tool and screen printing technology. The IDE surface was modified with the active layer of $\mathrm{ZnO}$ seed particle, further enhance the seed particle into the ZnO NRs. The structural, compositional and electrical properties were investigated with field emission scanning electron microscopy (FeSEM), atomic force microscopy (AFM) energy dispersive spectroscopy (EDS), Xray diffraction (XRD) technique and Keithley 4200 semiconductor

\footnotetext{
*Electrochemical Society Member.

zE-mail: akshayeliyana777@gmail.com
}

characterization system respectively. The sensor displayed a sensitivity of $1.06 \mathrm{nF} / \mathrm{pH}$ in the range of $\mathrm{pH} 4$ to $\mathrm{pH} 10$.

\section{Experimental and Methods}

Chemicals.-Zinc acetate dehydrate $\left(\mathrm{C}_{4} \mathrm{H}_{10} \mathrm{O}_{6} \mathrm{Zn}\right)$, Zinc nitrate hexahydrate $\left(\mathrm{H}_{12} \mathrm{~N}_{2} \mathrm{O}_{12} \mathrm{Zn}\right)$, Monoethanolamine (MEA) and Hexamethylenetetramine (HMT), the precursor material for the $\mathrm{ZnO}$ seed layer, were purchased from Sigma Aldrich. The IDEs structures are fabricated from Copper $(\mathrm{Cu})$ metal and non-conducting fiber epoxy used as a substrate.

Device characterization.-The surface morphology of $\mathrm{ZnO}$ seed layer with NRs and IDE structure were characterized using field emission scanning electron microscopy (FeSEM) with energy dispersive $\mathrm{X}$-ray spectroscopy (EDS). The crystallinity of ZnO NRs was examined using X-ray diffractometer (XRD) with peak intensities were in the range of $20^{\circ}$ to $70^{\circ}$ at $2 \theta$ degree angle in scanning rate. The ambient contact mode AFM imaging was performed on screen printed IDE using multimode nanoscope with IIIa controller (Bruker, Germany). The sensing characteristics of ZnO NRs grown IDE sensor was measured using a probe station (semiconductor parameter analyzer) connected to the computer at room temperature in ambient conditions. All the sensing data measurement were repeated and analyzed using four similar fabricated $\mathrm{ZnO} \mathrm{NRs}$ grown IDEs sensors.

Fabrication of IDE based pH sensor.-The complete fabrication process of $\mathrm{ZnO}$ NRs based IDEs sensor illustrated in Fig. 1. As a first step, the non-conducting fiber epoxy based printed circuit board (PCB) with the dimension of $16 \times 25 \mathrm{~mm}^{2}$ were ultrasonically cleaned. The IDEs structure has been screen printed on the fiber epoxy based printed circuit board with the finger length of $11 \mathrm{~mm}$, electrode width is $0.5 \mathrm{~mm}$ and spacing between two fingers is $0.5 \mathrm{~mm}$. The IDEs design has modeled and tested using CIRCAD software tool and prototype was shown in Fig. 2a. The copper $(\mathrm{Cu})$ paste can be fired at a low temperature, was used for this purpose. After the screen printing process, the IDEs layers were dried at $100^{\circ} \mathrm{C}$ for 30 minutes. The fabricated IDEs consist of total 18 individual electrodes and it will provide a total sensing area of about $18 \times 16 \mathrm{~mm}^{2}$ for the $\mathrm{ZnO}$ seed layer as shown in Fig. 2b. 


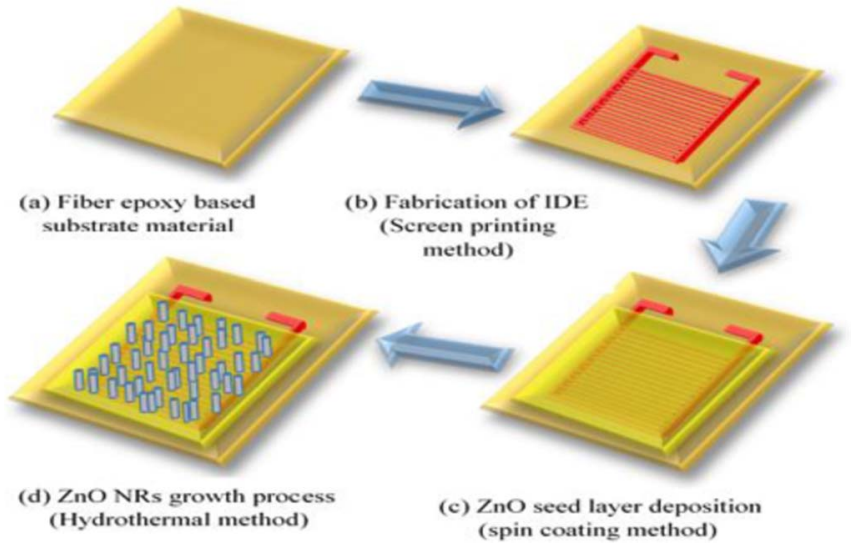

Figure 1. Schematic illustration of $\mathrm{ZnO}$ NRs based IDEs sensor fabrication process.

The uniform and stable $\mathrm{ZnO}$ seed particle solution was prepared and deposited on the $18 \times 16 \mathrm{~mm}^{2}$ active area of the IDEs structure. A temperature controlled spin coating unit was used to deposit the $\mathrm{ZnO}$ seed solution on the IDEs at 4,000 rpm for 30 seconds with four step programming process. The electrodes were dried in a muffle furnace at $160^{\circ} \mathrm{C}$ for 15 minutes. The same deposition process repeated four times to obtain a uniform pattern of $\mathrm{ZnO}$ seed layer on the IDEs surfaces.

The low temperature hydrothermal growth process of $\mathrm{ZnO} N R s$ is illustrated in flow chart 1 . The prepared growth solution consists of a mixed solution of the Zinc nitrate hexahydrate and hexamethylenetetramine (HMT)

In brief, $4.4 \mathrm{gm}$ of zinc nitrate hexahydrate added with the deionized water and $3.25 \mathrm{gm}$ of the hexamethylenetetramine (HMT). The $\mathrm{ZnO}$ NRs were grown by immersing the IDEs in the prepared aqueous solution using homemade Aluminium based sample holder. During this process, the solution was heated at $93^{\circ} \mathrm{C}$ for duration of 5 hours in a muffle furnace. ${ }^{26}$ After the growth process, the samples were neatly cleaned in deionized water and dried in room temperature.

\section{Results and Discussion}

Characterization of $\mathrm{ZnO}$ seed particles and $\mathrm{ZnO}$ NRs.-The surface morphology and chemical composition of the $\mathrm{ZnO}$ seed layer (Figs. 3a and 3b), ZnO NRs (Figs. 3c and 3d) and IDEs structure (Fig. 4) were analyzed using field emission scanning electron microscopy (FeSEM) with Energy dispersive spectrometer (EDS). The majority of the synthesized $\mathrm{ZnO}$ NRs grown uniformly in high compactness with proper alignment and perpendicular to the substrate. The top view of the image oriented like a hexagonal faceted morphology. The average length and diameters of the ZnO NRs are $1 \mu \mathrm{m}$ and
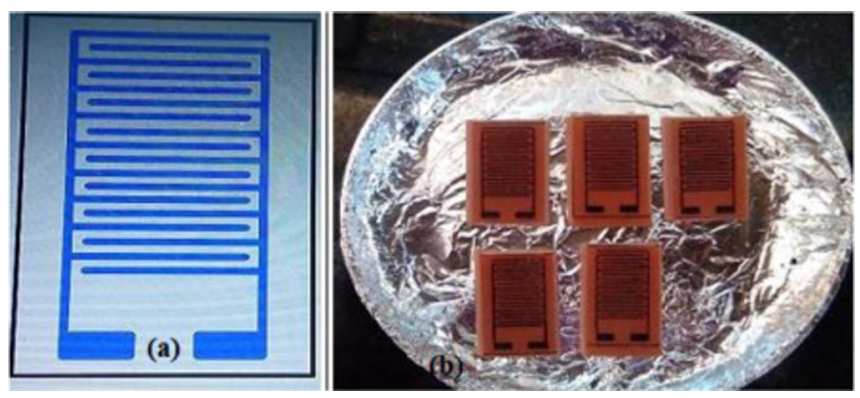

Figure 2. Schematic design of IDEs (a) and screen printed IDEs structures (b).

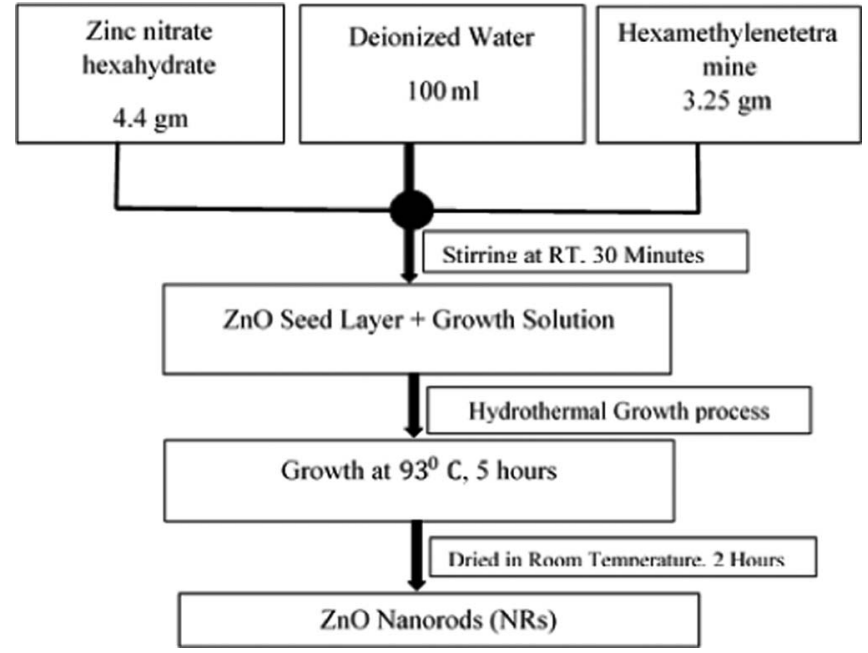

Flow chart 1. Hydrothermal ZnO NRs growth process flow chart.

$\approx 60 \pm 10 \mathrm{~nm}$. Most of these NRs shows branched structure, parent NRs further grew into smaller and narrow NRs. The size of the $\mathrm{ZnO}$ NRs is strongly dependent on the seed size of the prepared $\mathrm{ZnO}$ seed layer. As the grain size of the particle layer decreases, smaller sizes of $\mathrm{ZnO}$ NRs in diameter are grown and vice versa. The screen-printed IDEs pattern modeled and designed for $500 \mu \mathrm{m}$ finger gap of the electrodes. The finger gap of the IDEs patterns is approximately $460 \mu \mathrm{m}$ from the FeSEM image analysis (Fig. 4). The $40 \mu \mathrm{m}$ variations happened due to the non-aligned edges of the electrodes pattern.

The EDS analysis shows the presence of $\mathrm{Zn}$ and $\mathrm{O}$ elements in the $\mathrm{ZnO}$ seed particles (Fig. 5a). Additionally, very small peaks for carbon element have been found in the spectrum and it is from the substrate material but no other impurity was detected in the chemical compositional studies. The weight percentage of $\mathrm{Zn}$ and $\mathrm{O}$ in $\mathrm{ZnO}$ seed particles are 314.19 and 203.91 respectively. The further, grown $\mathrm{ZnO}$ NRs also composed of $\mathrm{Zn}$ and $\mathrm{O}$ elements only. Except for $\mathrm{Zn}, \mathrm{O}$ and $\mathrm{C}$, no other element has been found in the spectrum. The weight percentage of $\mathrm{Zn}$ and $\mathrm{O}$ in $\mathrm{ZnO}$ NRs were 422.89 and 214.54 respectively (Fig. 5b). The ZnO NRs contain 10-15\% more ZnO elemental composition compared to the $\mathrm{ZnO}$ seed particle.

Further, crystal phase and orientation of $\mathrm{ZnO}$ NRs were characterized using X-ray diffraction (XRD) technique. The peak intensities were measured in the range of $20^{\circ}$ to $70^{\circ}$ at $2 \theta$ degree angle in scanning rate. All the diffraction peaks observed in the $\mathrm{ZnO}$ NRs perfectly indexed and well matched with the standard Joint Committee on Powder Diffraction (JCPDS) card No.35-1451, which equivalent to the hexagonal morphology of $\mathrm{ZnO}$.

The XRD result shows the $\mathrm{ZnO}$ NRs consist strong diffraction peak at the (002) plane and its location is in $35.44^{\circ}$ degree angle as shown in Fig. 6. From that, $\mathrm{ZnO}$ NRs are in hexagonal wurtzite structures with high c-axis and the narrowest peak of full width at half maximum (FWHM). The obtained sharp peaks indicates that the ZnO NRs have an excellent crystal quality and its diffraction peaks were matching with the bulk $\mathrm{ZnO}$ material.

The average grain size of the $\mathrm{ZnO}$ NRs was calculated using Scherer's formula.

$$
\mathrm{D}=\frac{\mathrm{K} \lambda}{\mathrm{FWHM} \cos \theta}
$$

Here FWHM is the full width at half maximum of the respective peak in radian, and $\theta$ represents the diffraction peak angle. $K$ is the Scherer constant, which is dependent on the crystallite shape and can be considered as $0.9 ;{ }^{27} \lambda$ is the X-ray wavelength of the incident $\mathrm{Cu}$ $\mathrm{K} \alpha$ radiation, which is $0.154056 \mathrm{~nm} .^{28}$ The $\mathrm{ZnO}$ NRs that were grown on the surface of the IDEs produced the crystallite size of $54.18 \mathrm{~nm}$ and this result also was matching with the FeSEM studies. 


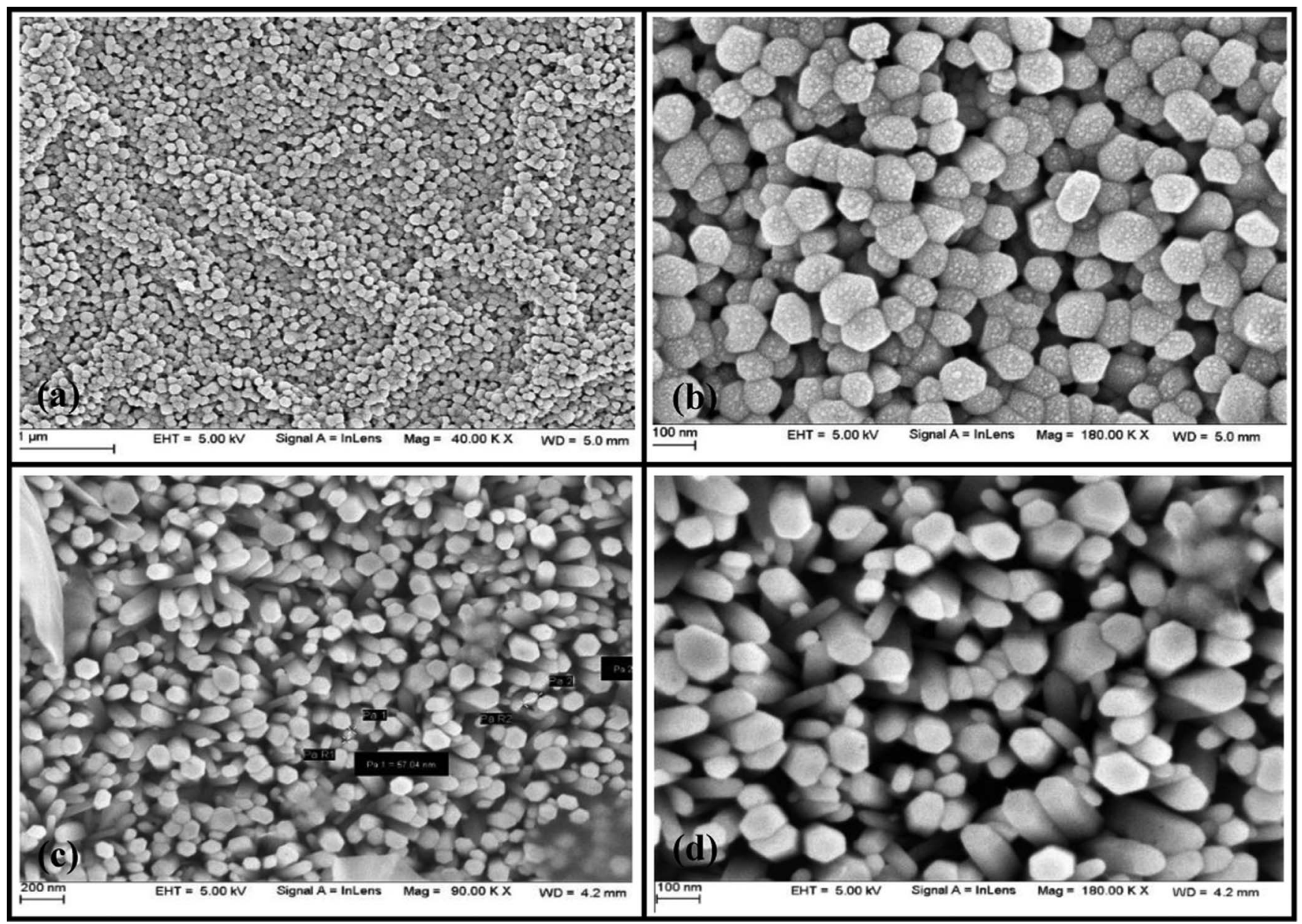

Figure 3. The FeSEM image of the $\mathrm{ZnO}$ seed layer (a \& b) and FeSEM image of the ZnO NRs over the IDEs structure (c \& d).

The surface morphological features of IDE electrode structure were performed and presented in the AFM analysis.

The surface roughness is a predominant parameter in adsorption and desorption of ions in the sensitive layer for electrochemical sensor applications. The root mean square surface roughness of the layer was estimated to be $204 \mathrm{~nm}$ from the surface and three dimensional (3D) topography images of IDEs as shown in Fig. 7.
Evaluation of sensing performance of as fabricated IDE sensor.-In order to measure the characteristics of the $\mathrm{pH}$ device, the two contact electrodes of the device was connected to the probe station using a Keithley 4200 semiconductor characterization system. The standard $\mathrm{pH}$ buffer solutions of $\mathrm{pH} 2$ to $\mathrm{pH} 12$ have been used for determine the $\mathrm{pH}$ sensors characteristics. The Fig. 8 shows the device characteristics measurement setup by using Keithley 4200 semiconductor
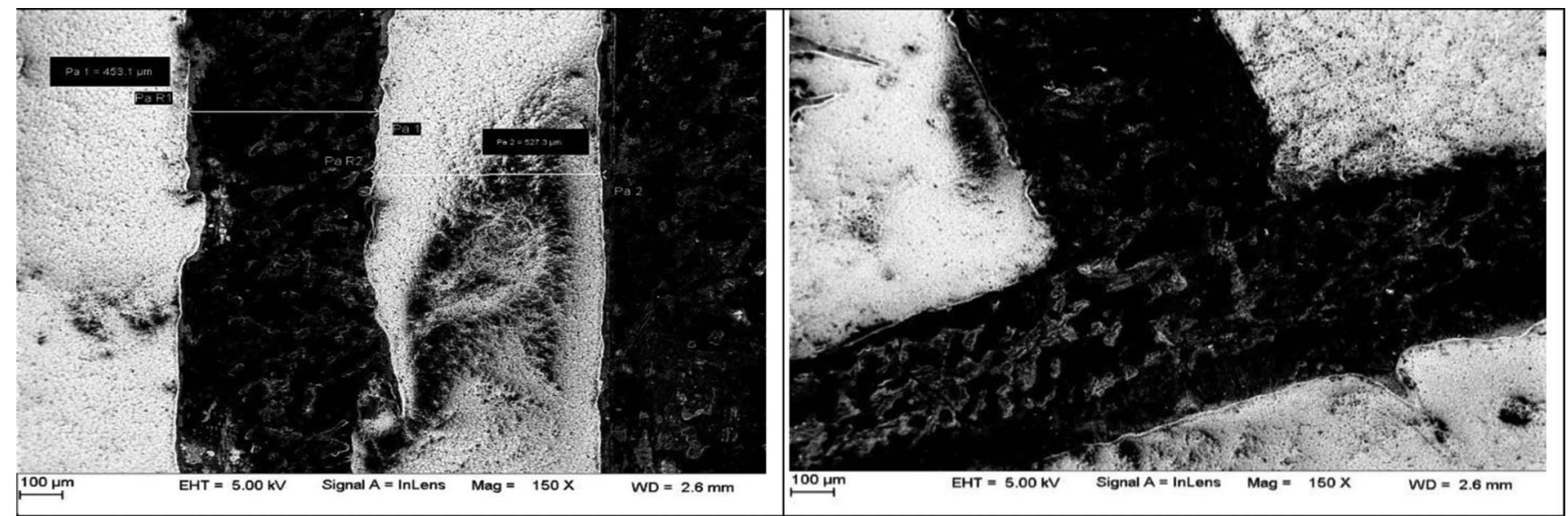

Figure 4. The FeSEM image of the screen printed IDEs. 


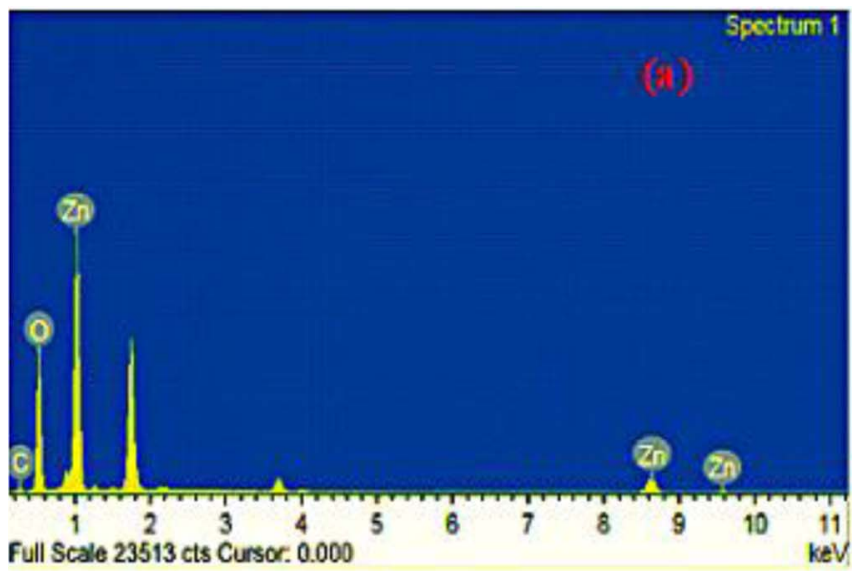

Figure 5. The EDS composition spectra for $\mathrm{ZnO}$ layer (a) and $\mathrm{ZnO}$ NRs (b).

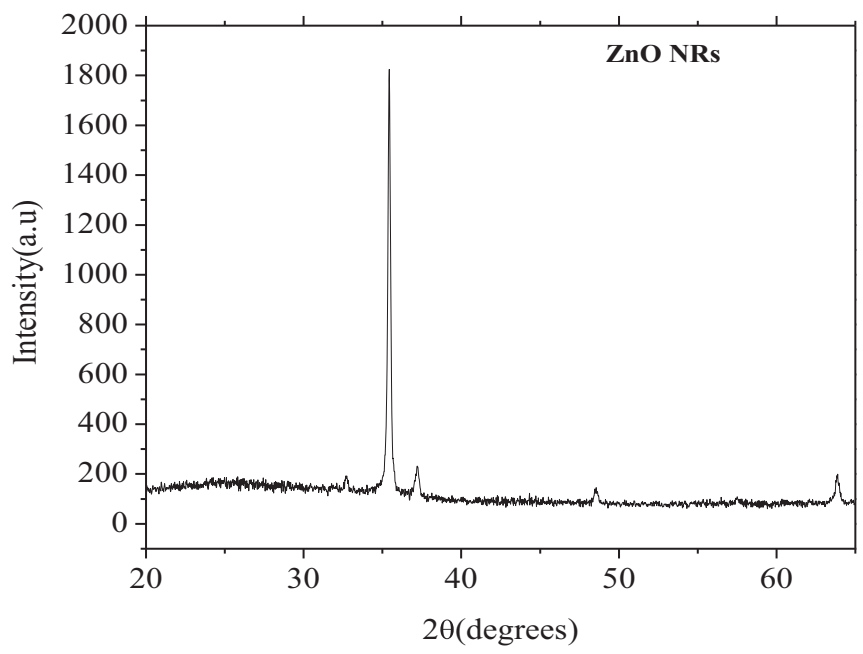

Figure 6. X-Ray diffraction patterns of $\mathrm{ZnO}$ NRs.

characterization system. To evaluate the sensing performance of the device, Capacitance-Voltage $(\mathrm{C}-\mathrm{V})$ and Capacitance-Frequency $(\mathrm{C}-\mathrm{F})$ characteristics of the sensor were performed with increasing $\mathrm{pH}$ concentrations from $\mathrm{pH} 2$ to $\mathrm{pH} 12$. Finally, the sensitivity of the device

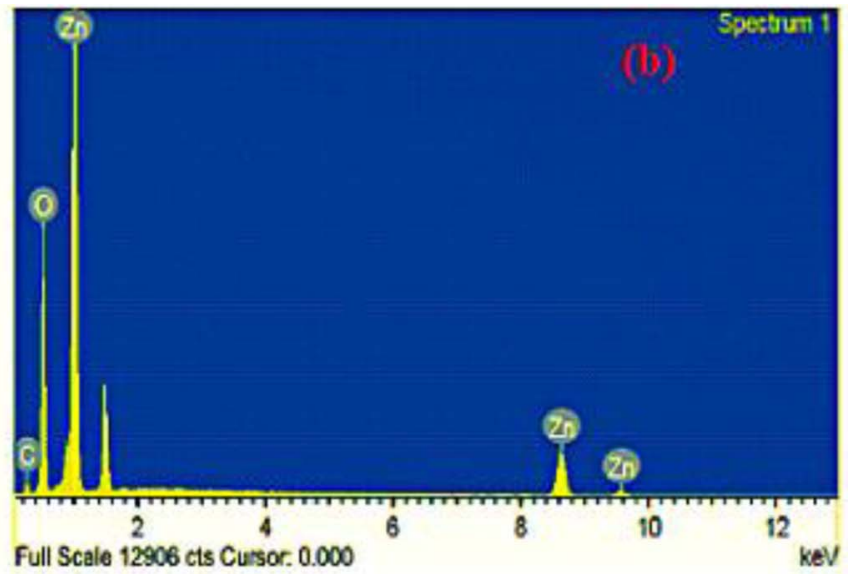

was estimated by plotting the graph of $\mathrm{pH}$ level $(\mathrm{pH})$ versus capacitance $(\mathrm{F})$ at applied frequency level of $1 \mathrm{KHz}$.

Here we have used two-contact electrode arrangement with IDEs platform for the $\mathrm{pH}$ sensor. When $0 \mathrm{~V}$ to $3 \mathrm{~V}$ range voltage is applied across the contact electrodes of the IDEs, the local electrical field generated on each digit induces in the micro gap electrodes, changes in the electrical properties of the active layer. While varying the $\mathrm{pH}$ concentration of the solution, the positive or negative charged surface groups of the electrical double layer (EDL) formed at the interface of $\mathrm{ZnO} \mathrm{NRs}$, electrolyte gets disturbed and which further leads to change in the electrical properties of the active layer. ${ }^{14}$

Fig. 9 shows the capacitance measured between the interdigitated microelectrodes are plotted against the voltage frequency with voltage ranging from the $-6 \mathrm{~V}$ to $5 \mathrm{~V}$ to confirm the capacitive nature of the fabricated IDEs. The value of the capacitance is almost stable in the range of $0 \mathrm{~V}$ to $5 \mathrm{~V}\left(1.9 \times 10^{-11} \mathrm{~F}\right)$.

Fig. 10 reveals that the $\mathrm{pH}$ buffer solution of capacitance measurements obtained and plotted against the voltage frequency ranging from $1 \mathrm{KHz}$ to $100 \mathrm{KHz}$. According to the Coulomb's law, $\mathrm{C}=\mathrm{q} / \mathrm{v}$, the chance of electrons passing across the electrode will increases when there is a low frequency of a voltage applied. ${ }^{29}$ The resistivity is inversely proportional to the conductivity which means, the conductivity will be increased, and hence interactions of more hydrogen ions will cause low resistivity according to the theory of conductivity. ${ }^{30}$
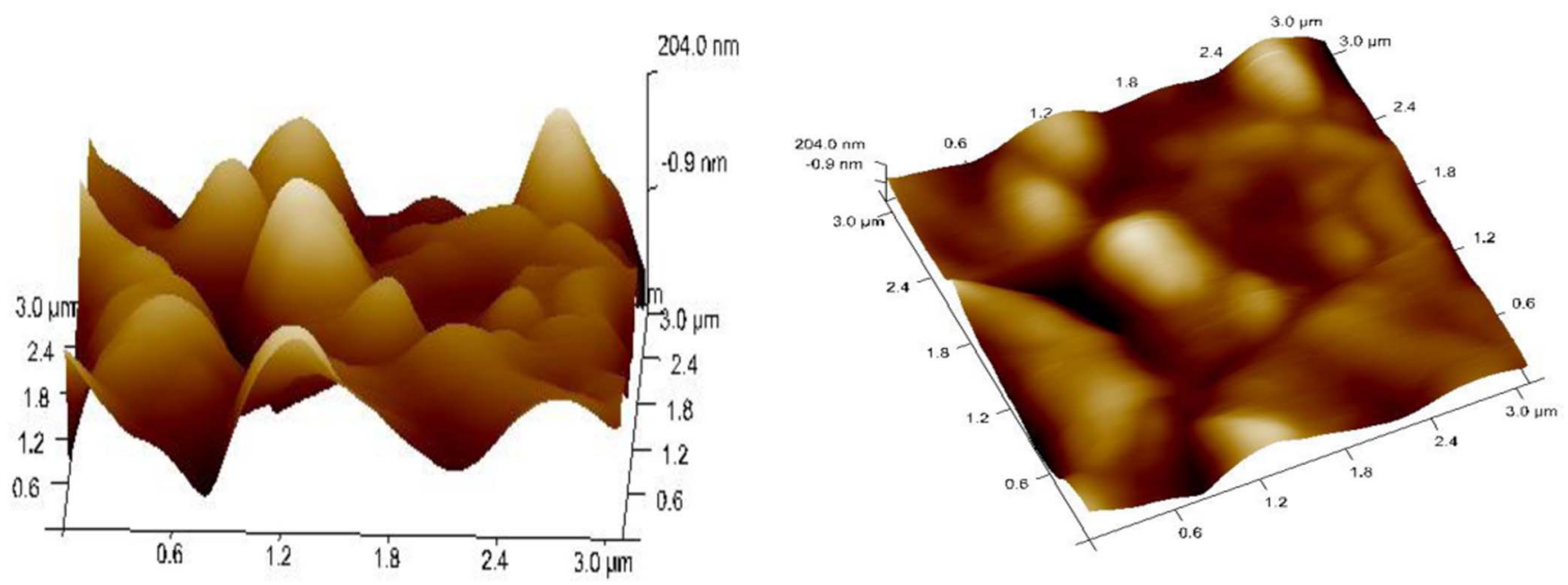

Figure 7. The 2D and 3D AFM images of the IDEs pattern. 


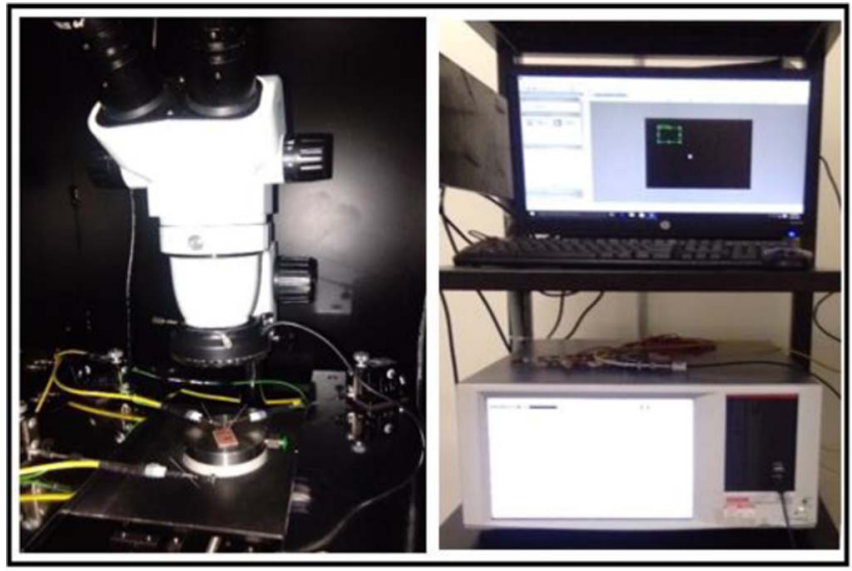

Figure 8. The $\mathrm{pH}$ sensor charcterstics maesuremnt setup using Keithley 4200 semiconductor characterization system.

From the obtained data the capacitance decreases with increasing frequency $(1 \mathrm{KHz}$ to $3 \mathrm{KHz}$ ) and further from $4 \mathrm{KHz}$ onwards the capacitance value is almost constant. In addition, it can be observed from Fig. 11, the fabricated sensor exhibits the decreases capacitance value $(9.65 \mathrm{nF}$ to $13.07 \mathrm{pF})$ with increases in the $\mathrm{pH}$ value $(\mathrm{pH} 2$ to $\mathrm{pH} 12)$ of the solution selected frequencies $(1 \mathrm{KHz}, 2 \mathrm{KHz}, 3 \mathrm{KHz}$, $4 \mathrm{KHz}, 5 \mathrm{KHz})$.

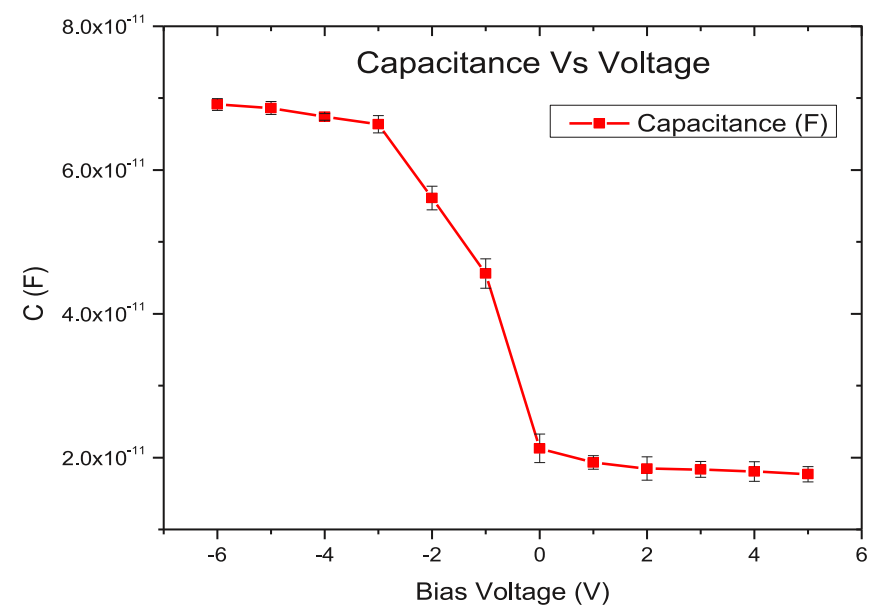

Figure 9. The C-V Measurement of the IDEs.

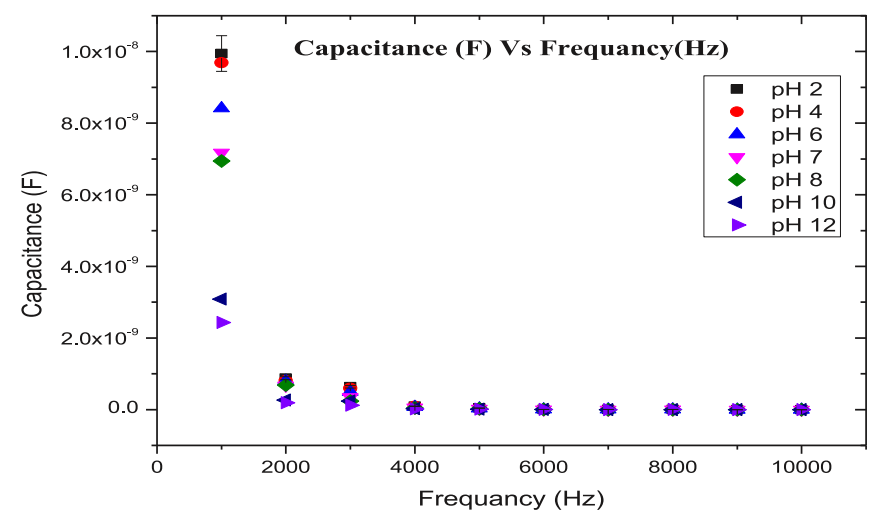

Figure 10. The C-F measurement at a different frequency.

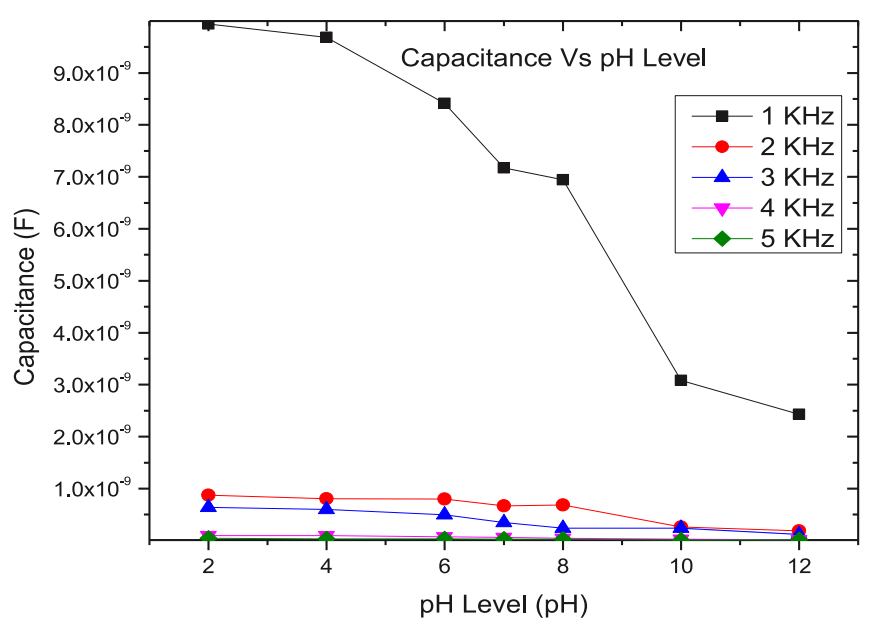

Figure 11. The change in capacitance with $\mathrm{pH}$ solution with selected frequencies.

Further to calculate the linear fit and sensitivity of the fabricated $\mathrm{ZnO}$ NRs based IDEs pH sensor, a corresponding curve (average capacitance $\mathrm{Vs} \mathrm{pH}$ concentration) of $\mathrm{C}-\mathrm{pH}$ characteristics as shown in Fig. 12. As seen in the plot, the fabricated IDE sensor detected $\mathrm{pH}$ in the linear $\mathrm{pH}$ range from 4-10 with a good correlation coefficient $\left(\mathrm{R}^{2}\right)$ of 0.8203 . From the obtained slope, sensor showed a sensitivity of $1.06 \mathrm{nF} / \mathrm{pH}$ in the range of $\mathrm{pH} 4$ to $\mathrm{pH} 10$.

To estimate the response time of the fabricated $\mathrm{pH}$ device, the sensor was immersed in standard $\mathrm{pH}$ buffer solutions whose $\mathrm{pH}$ values were 4, 6, 8 and 10 respectively. The Keithley 4200 semiconductor characterization system used to record the response time of the sensor. The experiment was repeated four times and the response time of the fabricated $\mathrm{pH}$ device was found about $1 \mathrm{~S}$ to $10 \mathrm{~S}$ for acidic and alkaline solutions. Their response speed much faster in acid solutions than alkaline solutions.

The Fig. 13a reveals the relative experiments of fabricated device in order to observe the stability of the device in various acid and alkaline solutions. The every experiment was continued for the time of $2100 \mathrm{~S}$, and the result was recorded every $300 \mathrm{~S}$ in the semiconductor characterization system. The analysis results confirm the fabricated device becomes highly stable in $\mathrm{pH} 6$ to $\mathrm{pH} 8$ and in higher acidic and alkali solutions it produce small variations in the results. Also the stability of the fabricated device tested for the long periods. In a week, the $\mathrm{pH}$ values of buffered solutions were measured in interval of a day and the obtained results once again confirms the good stability of the fabricated device.

To test the device reproducibility, we have fabricated three more IDE NRs based $\mathrm{pH}$ sensors namely IDE NRs ${ }_{2}$, IDE NRs ${ }_{3}$ and IDE $\mathrm{NRs}_{4}$ with IDE NRs ${ }_{1}$ is the first fabricated device. The change in capacitance with respect to $\mathrm{pH}$ solution of the three devices with constant frequency of $1 \mathrm{KHz}$ as shown in Fig. 13b. The results confirms the difference between fabricated IDE NRs ${ }_{1}$ with the second third and fourth IDE NRs devices are $0.8 \%, 1.3 \%$ and $0.7 \%$, which is an acceptable error margin of less than $<2 \%$. The obtained results confirms the fabricated $\mathrm{pH}$ sensor possess good stability for repetitive detection of $\mathrm{pH}$ and are remarkably reliable.

\section{Conclusions}

Herein, we report the design and fabrication of $\mathrm{ZnO}$ NRs based IDEs senor using hydrothermal growth of $\mathrm{ZnO}$ nanorods (NRs) were successfully implemented. Spin coating deposition of $\mathrm{ZnO}$ seed layer followed by the hydrothermal growth of $\mathrm{ZnO}$ nanostructures having NRs morphology lead to the fabrication and characterization of the sensor. The structural, compositional and electrical properties of the NRs based IDEs structures were investigated and examined by using field emission scanning electron microscopy (FeSEM), atomic 

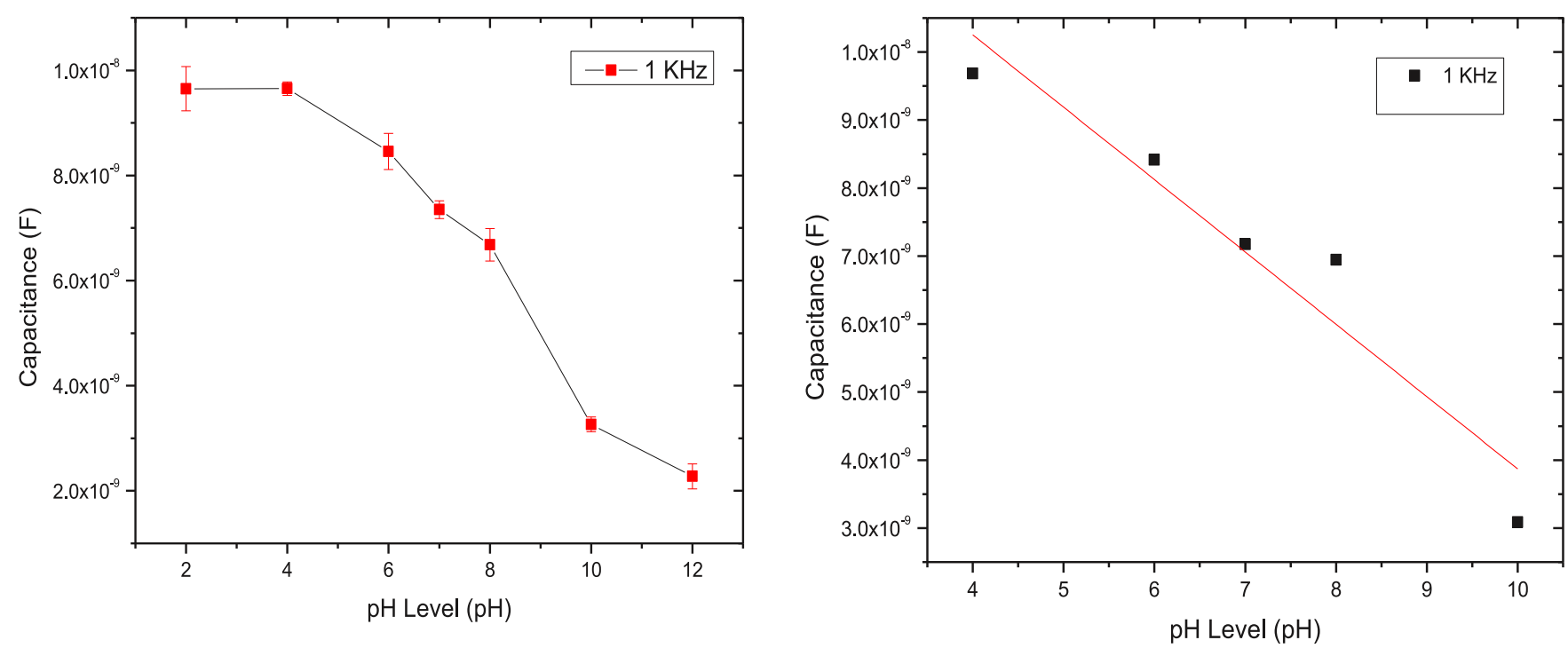

Figure 12. The Linear fit of change in capacitance in the region of $\mathrm{pH} 4-10$ at $1 \mathrm{KHz}$.

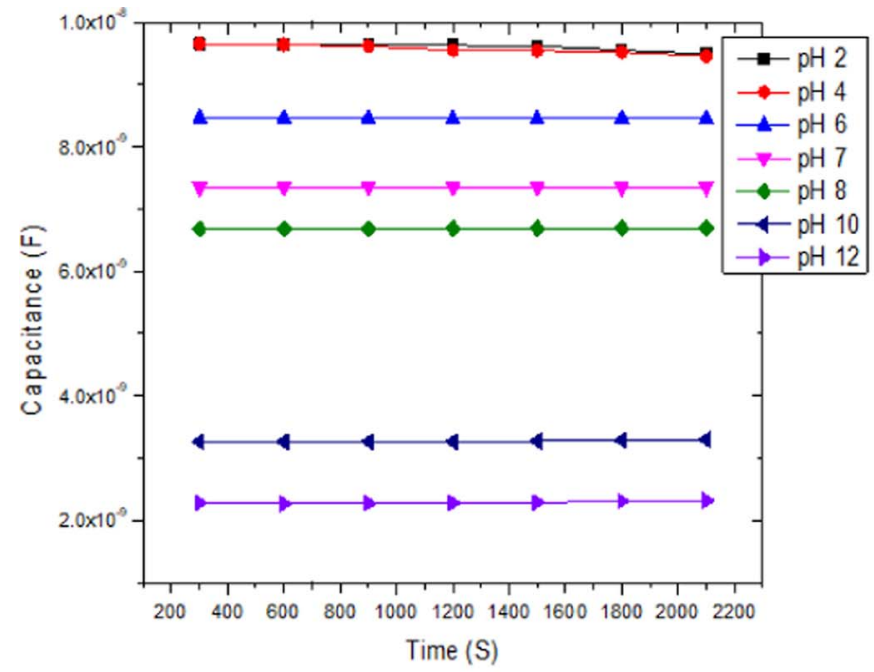

(a)

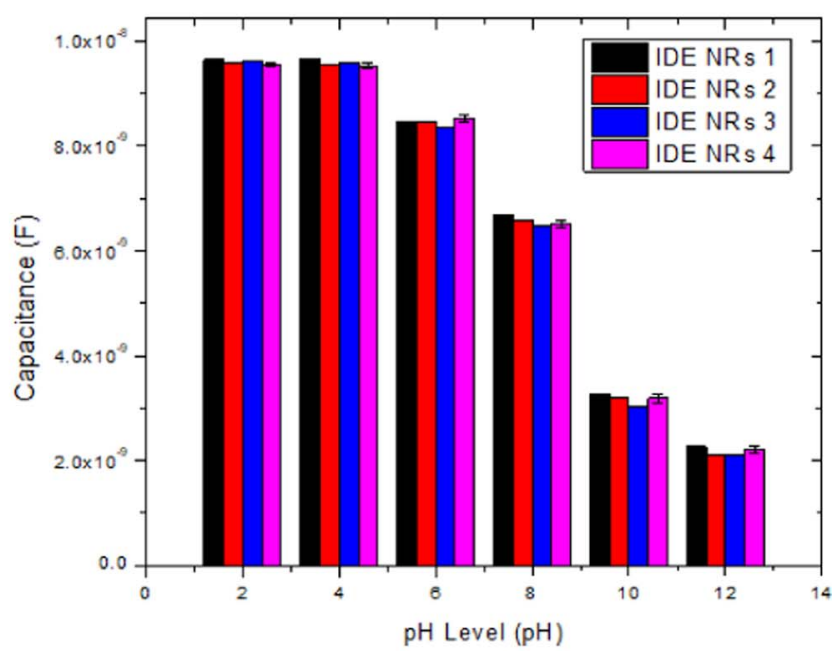

(b)

Figure 13. Stability of the fabricated IDE NRs ${ }_{1} \mathrm{pH}$ sensor (a) and Reproducibility of the fabricated IDE NRs pH sensors (b).

force microscopy (AFM), energy dispersive spectroscopy (EDS), Xray diffraction (XRD) technique and Keithley 4200 semiconductor characterization system respectively. The sensing performance of the IDEs, the sensor capacitance decreases with increasing frequency $(1 \mathrm{KHz}$ to $3 \mathrm{KHz}$ ) and further frequency from $4 \mathrm{KHz}$ onwards the capacitance value is almost constant and negligible. It also exhibits the decreases capacitance value $(9.94 \mathrm{nF}$ to $13.07 \mathrm{pF})$ with increases in the $\mathrm{pH}$ value ( $\mathrm{pH} 2$ to $\mathrm{pH} 12)$ of the solution at selected frequencies $(1 \mathrm{KHz}, 2 \mathrm{KHz}, 3 \mathrm{KHz}, 4 \mathrm{KHz}, 5 \mathrm{KHz})$. The sensor showed a sensitivity of $1.06 \mathrm{nF} / \mathrm{pH}$ in the range of $\mathrm{pH} 4$ to $\mathrm{pH} 10$. The $\mathrm{ZnO}$ NRs based IDEs $\mathrm{pH}$ sensor present it as with simple fabrication process, low-cost, and convenient device for measurement of $\mathrm{pH}$ in water.

\section{Acknowledgments}

We would like to thank the Department of Science and Technology (DST), for the INSPIRE FELLOWSHIP (Registration Number: IF170544) and University grant Commission (194-3/2016(IC)) sponsored the Indo-US Bilateral Research project for funding and instruments facilities provided to this research work.

\section{ORCID}

Shekhar Bhansali (1D) https://orcid.org/0000-0001-5871-9163

\section{References}

1. G. M. Sanches, P. S. G. Magalhaes, A. Z. Remacre, and H. C. J. Franco, Potential of apparent soil electrical conductivity to describe the soil $\mathrm{pH}$ and improve lime application in a clayey soil. Soil Tillage Res. 175, 217 (2018).

2. M. Simic, L. Manjakkal, K. Zaraska, G. Stojanovic, R. Dahiya, and $\mathrm{TiO}_{2}$ Based Thick Film pH Sensor, IEEE Sens. J., 1 (2016).

3. T. M. Pan, C. W. Wang, S. Mondal, and S. T. Pang, Super-Nernstian sensitivity in microfabricated electrochemical $\mathrm{pH}$ sensor based on CeTixOyfilm for biofluid monitoring. Electrochim. Acta, 261, 482 (2018).

4. Z. Dong, U. C. Wejinya, and I. H. Elhajj, Fabrication and testing of ISFET based pH sensors for microliter target solutions. Sensors Actuators, A Phys. 194, 181 (2013).

5. R. V. Benjaminsen, H. Sun, J. R. Henriksen, N. M. Christensen, K. Almdal, and T. L. Andresen, Evaluating nanoparticle sensor design for intracellular $\mathrm{pH}$ measurements. ACS Nano, 5, 5864 (2011).

6. M. Michalak, M. Kurel, J. Jedraszko, D. Toczydlowska, G. Wittstock, M. Opallo, W. Nogala, and Voltammetric pH Nanosensor, Anal. Chem., 87 (2015).

7. P. Salvo, N. Calisi, B. Melai, B. Cortigiani, M. Mannini, A. Caneschi, G. Lorenzetti, C. Paoletti, T. Lomonaco, A. Paolicchi, I. Scataglini, V. Dini, M. Romanelli, R. Fuoco, and F. Di Francesco, Temperature and $\mathrm{pH}$ sensors based on graphenic materials. Biosens. Bioelectron., 91, 870 (2017). 
8. C. Nie, A. Frijns, M. Zevenbergen, and J. Den Toonder, An integrated flexmicrofluidic-Si chip device toward sweat sensing applications. Sensors Actuators, B Chem. 227, 427 (2016).

9. H. Kahlert, T. Steinhardt, J. Behnert, and F. Scholz, A new calibration free pH-probe for in situ measurements of soil pH. Electroanalysis, 16, 2058 (2004).

10. Y. H. Liao and J. C. Chou, Fabrication and Characterization of a Ruthenium Nitride Membrane for Electrochemical pH Sensors. Sensors, 9, 2478 (2009).

11. A. Fulati, S. M. Usman Ali, M. Riaz, G. Amin, O. Nur, and M. Willander, Miniaturized pH sensors based on zinc oxide nanotubes/nanorods. Sensors, 9, 8911 (2009).

12. M. Moises, M. Velasco, E. Mart, and H. L. Mart, ISFET sensor characterization. Procedia Engineering, 35, 270 (2012).

13. L. Manjakkal, K. Cvejin, J. Kulawik, K. Zaraska, and D. Szwagierczak, Electrochemical interdigitated conductimetric ph sensor based on $\mathrm{RuO} 2$ thick film sensitive layer. EPE 2014 - Proc. , 2014 Int. Conf. Expo. Electr. Power Eng., 797 (2014).

14. L. Manjakkal, K. Cvejin, J. Kulawik, K. Zaraska, R. P. Socha, and D. Szwagierczak, Xray photoelectron spectroscopic and electrochemical impedance spectroscopic analysis of RuO2-Ta2O5thick film pH sensors. Anal. Chim. Acta, 931, 47 (2016)

15. L. Manjakkal, B. Sakthivel, N. Gopalakrishnan, and R. Dahiya, Printed flexible electrochemical pH sensors based on $\mathrm{CuO}$ nanorods. Sensors Actuators, B Chem. 263, 50 (2018).

16. M. L. Zhong, D. C. Zeng, Z. W. Liu, H. Y. Yu, X. C. Zhong, and W. Q. Qiu, Synthesis, Growth mechanism and gas-sensing properties of large-scale $\mathrm{CuO}$ nanowires. Acta Mater. 58, 5926 (2010).

17. K. Arshak, E. Gill, A. Arshak, and O. Korostynska, Investigation of tin oxides as sensing layers in conductimetric interdigitated $\mathrm{pH}$ sensors. Sensors Actuators, B Chem. 127, 42 (2007).

18. A. B. Rosli, Z. Awang, S. S. Shariffudin, and S. H. Herman, Fabrication of integrated solid state electrode for extended gate-FET $\mathrm{pH}$ sensor. Mater. Res. Express, 6, 1 (2019).

19. S. J. Young, C. C. Yang, and L. T. Lai, Review-Growth of Al, Ga, and In-Doped ZnO Nanostructures via a Low-Temperature Process and Their Application to Field Emission Devices and Ultraviolet Photosensors. J. Electrochem. Soc., 164, B3013 (2016)
20. L. Ji, C. Wu, C. L. Ã, T. Meen, and K. Lam, Characteristic Improvements of ZnOBased Metal - Semiconductor - Metal Photodetector on Flexible Substrate with ZnO Cap Layer. Japanese Journal of Applied Physics, 49, 1 (2010).

21. R. Ahmad, M. S. Ahn, and Y. B. Hahn, ZnO nanorods array based field-effect transistor biosensor for phosphate detection. J. Colloid Interface Sci., 498, 292 (2017).

22. K. L. Foo, U. Hashim, K. Muhammad, and C. H. Voon, Sol - gel synthesized zinc oxide nanorods and their structural and optical investigation for optoelectronic application. Nanoscale Res. Lett. 9, 1 (2014).

23. C. H. Hsiao, C. S. Huang, S. J. Young, S. J. Chang, J. J. Guo, C. W. Liu, and T. Y. Yang, Field-emission and photoelectrical characteristics of Ga-ZnO nanorods photodetector. IEEE Trans. Electron Devices, 60, 1905 (2013).

24. T. P. Chen, S. J. Young, S. J. Chang, C. H. Hsiao, L. W. Ji, Y. J. Hsu, and S. L. Wu, Low-frequency noise characteristics of $\mathrm{ZnO}$ nanorods schottky barrier photodetectors. IEEE Sens. J., 13, 2115 (2013).

25. T. P. Chen, S. J. Young, S. J. Chang, C. H. Hsiao, and Y. J. Hsu, Bending effects of $\mathrm{ZnO}$ nanorods metal-semiconductor-metal photodetectors on flexible polyimide substrate. Nanoscale Res. Lett., 7, 1 (2012).

26. S. K. N. Kumar, A. A. Kumar, A. A. Aniley, S. Bhansali, and R. E. Fernandez, Hydrothermal Growth of Zinc Oxide ( $\mathrm{ZnO}$ ) Nanorods (NRs), Structural, and Chemical Composition Studies for $\mathrm{pH}$ Measurement Sensor Applications. ECS Trans. 88, 437 (2019).

27. H. Metin and R. Esen, Annealing effects on optical and crystallographic properties of CBD grown CdS films. Semicond. Sci. Technol., 18, 647 (2003).

28. N. V. Kaneva and C. D. Dushkin, Preparation of nanocrystalline thin films of $\mathrm{ZnO}$ by sol-gel dip coating. Bulg. Chem. Commun., 43, 259 (2011).

29. T. K. Lin, Fabrication of Interdigitated Electrodes (IDE's) by Conventional Photolithography Technique for $\mathrm{pH}$ Measurement Using Micro-Gap Structure. 1570016883, 8(2014).

30. M. A. Schreiber, K. L. Moyer, B. J. Mueller, M. A. Ramos, J. S. Green, L. White, W. Hedgepeth, K. Juliano, J. R. Scull, and P. K. Hovsepian, Development and validation of a cholate binding capacity method for DMP 504, a bile acid sequestrant. J. Pharm. Biomed. Anal., 25, 343 (2001). 